\title{
SAR-COV-2 Pandemic
}

\section{Eghon $G^{*}$}

University of Chile, Chile

*Corresponding author: Eghon Guzman B, University of Chile, Chile, Email: eguzmanb@ gmail.com

\section{Editorial}

Since time immemorial, several centuries before Christ, humanity has faced plagues and pandemics that have decimated the world population, just remember the plague of Athens in $430 \mathrm{BC}$, several plagues have put human survival. We cannot forget smallpox that killed 300 million people; measles killed around 200 million human beings, the Spanish flu that is estimated at between 50 and 100 million. We have survived the black plague, bubonic plague, diphtheria, yellow fever, malaria, cholera, Ebola, tuberculosis, hanta virus, dengue and one of the most recent HIV, which already as 35 million deaths.

We are surrounded by many germs, we live with them, including bacteria and viruses, this last time we face swine flu, avian flu, SARS, H1N1 that have plagued us and have forced us to search through research for some very effective treatments and others that still do not allow us to cure $100 \%$. Today we face the covid-19 with the uncertainty of the scope and impact it will have on the world; in December 2019 an outbreak of pneumonia of unknown etiology emerged in China $[1,2]$.

The pathogen was identified as a new SARS-CoV-2 virus corona, called COVID-19 by the World Health Organization (WHO), which causes a Severe Acute Respiratory Syndrome, severely affects the lower respiratory tract and manifests as a pneumonia [3].

Phylogenetic analysis performed the genome sequence this new SARS-CoV-2 coronavirus, and an angiotensinconverting enzyme 2 (ACE2) was identified as the functional receptor for SARS-CoV-2 and ACE2 mRNA is known to be present in practically all organs (oral and nasal mucosa, nasopharynx, lung, stomach, small intestine, colon, skin, lymph nodes, thymus, bone marrow, brain, kidney).

In conclusion, ACE2 is abundantly present in humans in epithelia of the lung and small intestine, which could provide possible entry routes for SARS-CoV-2. This epithelial expression, together with the presence of ACE2 in the vascular endothelium, provides us with a first step in understanding the pathogenesis of the main manifestations of SARS disease [4]. Given that to date we do not have a definitive vaccine for covid-19, and that this pathology does not have an effective treatment, it is important to highlight that its complications are rapidly progressive and generate a public health problem. This pandemic has definitely shown that we are as vulnerable a species as the others. As a public health problem, one of the priority aspects in a pandemic is that the main decisions must be based on the greatest scientific evidence available, which is why the role of experts is crucial; it is essential to ensure the reliability, transparency of information, we must have unique and reliable leadership. Communication with the community must be fluid, permanent, timely, open and regular. Protection of health workers is essential. The team from primary care, laboratory centers, and taking exams, emergency services, hospitalization and intensive care units, self-care measures takes on a transcendent importance. Health authorities must ensure the protection of people's privacy. The general ethical guidelines allow us to anticipate very difficult decisions, proper planning of equipment and infrastructure is vital, concern for the health team is paramount, clinical management and communication with the patient and his family must be complete, evaluating the principle of patient autonomy. Intensive treatment should be proportionate to the preconditions. The accompaniment and permanent communication with the patient and the family must allow the principles of privacy, dignity and care that it requires. Finally, the centrality of the person must be those that guide these ethical guidelines.

\section{References}

1. Sobrabi Alsafi Z, O'Neill N, Khan M, Kerwan A, Al-Jabir A, et al. (2020) World Health Organization declares global emergency: A review of the 2019 novel coronavirus (COVID-19). Int J Surg 76: 71-76.

2. Chen Y, Liu Q Gu D (2020) Emerging Coronaviruses: 


\section{Journal of Embryology \& Stem Cell Research}

Genome Structure, Replication, and Pathogenesis. Medical virology 92(4): 418-423.

3. Lu R, Zhao X, Li J, Niu P, Yang B, et al. (2020) Genomic Characterisation and Epidemiology of 2019 Novel
Coronavirus: Implications for Virus Origins and Receptor Binding. 395(10224): 565-574.

4. (2020) Social Table Covid-19, Chile Government. 